UNIMONTES

Osmar Pereira Oliva**

UNIMONTES

\title{
Rachel Queiróz e Conceição de 0 Quinze: Mulheres que buscam refundar a tradição por meio da insubordinação feminina
}

Resumo:

A partir da perspectiva dos estudos culturais de gênero e da teoria feminista, este breve estudo busca contribuir para a desconstrução do discurso canônico produzido pelo imaginário masculino a partir de uma releitura de $O$ Quinze, de Rachel de Queiróz, tomando a voz dissidente e o corpo fragmentado da protagonista Conceição como lugar de resistência e insubordinação feminina.

Palavras-chave:

escrita feminina, insubordinação, desconstrução do cânone

\section{Abstract:}

From the perspective of cultural and gender studies and feminist theory, this brief study aims to contribute to the deconstruction of the canonical discourse produced by the male imagination from a reinterpretation of $O$ Quinze, by Rachel de Queiróz, taking the dissenting voice and the fragmented body of the protagonist Conceição as a place of resistance and female insubordination.

Keywords:

female writing, insubordination, deconstruction of the canon

Historicamente, o discurso opressor construído socialmente com base na dominação masculina e patriarcal forjou a ideia de que a mulher era um ser biologicamente inferior e frágil. Um segundo sexo, fraco e sem razão, forçado à passividade, subjugado ao desejo do homem e incapaz de ocupar espaço na esfera pública.

Esse imaginário constituído pelo gênero masculino foi decisivo na construção do cânone da literatura brasileira, visto que até meados do século XIX, apenas os homens tinham acesso à educação formal e as mulheres estavam à margem da sociedade devido a aspectos políticos, 
econômicos e sociais. De acordo com Nádia Battella Gotlib, "ao homem era de praxe se 'ensinar a ler, a escrever e a contar', e à mulher, 'a coser, lavar, a fazer rendas e todos os misteres femininos', que incluía a reza" (Gotlib 2003: 27).

Vagarosamente, em função das mudanças promovidas pelo progresso tecnológico, é que a mulher começa a sair do espaço privado e a estudar dentro dessa sociedade fechada e machista. Algumas dessas mulheres que conseguiram o direito a uma educação diferenciada foram influenciadas pelas ideias feministas que já circulavam na Europa o que garantiu o direito de inclusão de novas vozes como Mary Wollstonecraft, escritora inglesa que inspirou Nísia Augusta Floresta para a acomodação das mesmas no cenário brasileiro, além de outras mulheres que contribuíram para sinalizar profundas mudanças no campo intelectual, no terreno literário e no modo de pensar da sociedade.

É naquele momento que a mulher começou a escrever e a participar significamente na literatura do país, no entanto ainda estava longe de ganhar um papel importante na nossa história literária. Para tanto, é preciso lembrar que apenas uma pequena elite tinha acesso à língua escrita no país, e que essa elite era composta em maioria pelo gênero masculino, de modo que, tanto a figura da leitora quanto da autora eram restritas ou simplesmente não existiam.

Por terem sido ignoradas por tanto tempo, a nossa tradição literária desconsiderou o talento criativo da mulher, centrando-a no dom artístico do homem. Por esse motivo, as mulheres foram apagadas e silenciadas e a maior parte de sua história contada por homens. Segundo Rita Terezinha Schmidt,

Excluída da órbita da criação, coube à mulher o papel secundário da reprodução. Essa tradição de criatividade androcêntrica que perpassa nossas histórias literárias assumiu o paradigma masculino da criação e, concomitantemente, a experiência masculina como paradigma da existência humana nos sistemas simbólicos de representação. (Schmidt 1995: 184)

O apagamento produzido pelo cânone literário deixou fora de seus escopos escritoras de nossa literatura que mereciam um lugar de estudo na formação de nossa identidade literária e cultural. Nesse sentido, acreditamos na necessidade de resgatar obras e autoras dissidentes, democratizando e igualando materiais culturais que acabaram sendo esquecidos ou não contemplados pela crítica literária. Para Zahidé Lupinacci Muzart, a falta de um espaço propício para suas criações custou caro às mulheres, pois "não ousando inovar, as mulheres submeteram-se aos cânones masculinos. E, imitando-os, para se integrarem na corrente, também não foram reconhecidas nem respeitadas e sim, esquecidas, mortas" (Muzart 1995: 87).

A pretensão deste breve estudo não é discutir o lugar canônico que alguns escritores ocupam na nossa tradição nem desconsiderar as obras "sagradas" da nossa literatura, pois estas se referem a escritores de grande valor estético e literário que resistiram ao tempo. No que toca à questão de gênero, observa-se que a mulher, em decorrência dos discursos ideológicos de poder proferidos pelo gênero masculino, foi deixada à margem permitindo, assim, a falta de reconhecimento e visibilidade de seus textos. 
Sem a intenção de questionar quem deve ficar dentro ou fora do cânone, mas para entender as lacunas deixadas pelo apagamento das mulheres dentro da literatura brasileira, foi preciso, pois, revisitar esta história para entender a violência aplicada à subjetividade feminina numa sociedade patriarcal. Pois é evidente que o valor literário de uma obra não depende do sexo do autor, mas do talento de cada um.

Assim, este retorno ao passado por meio de uma revisão crítica historiográfica sobre a representação do feminino nos textos literários produzidos por mulheres no Brasil contribui para a desconstrução do discurso canônico produzido pelo imaginário masculino e possibilita um olhar da própria mulher sobre si mesma, pois segundo Lygia Fagundes "sempre fomos o que os homens disseram o que nós éramos. Agora somos nós que vamos dizer o que nós somos" (Telles apud Coelho 1993: 14).

Ao se posicionar como sujeito ativo e criativo, as mulheres escritoras puderam dar voz a personagens a partir da perspectiva feminina e repensar o sujeito feminino além da tradicional representação literária. Partindo dessa premissa de subversão aos valores e normas patriarcais criadas pela tradição literária masculina, pretendemos fazer uma releitura da narrativa O Quinze, de Rachel de Queiróz, para discutir como a presença dessa voz consciente representa a figura feminina e a escritura do corpo a partir da perspectiva da personagem Conceição.

Dentro deste campo fecundo de ideias sobre a emancipação da mulher na sociedade, Rachel de Queiróz se destaca por ter sido uma das primeiras mulheres de sua época a se aventurar no terreno das letras, praticando uma atividade considerada exclusivamente masculina e se colocando como sujeito de voz ativa. Por se confrontar com uma tradição literária criada por homens, o romance $O$ Quinze, publicado em 1930, gerou dúvidas quanto a sua autoria, pois houve quem duvidasse da capacidade de uma mulher, quanto mais sendo tão jovem, ter tido condições de escrever uma obra tão bem tecida. De acordo com Constância Lima Duarte citada por Graciliano Ramos (2003):

O Quinze caiu de repente ali por meados de 30 e fez nos espíritos estragos maiores que o romance de José Américo, por ser livro de mulher e, o que na verdade causava assombro, de mulher nova. Seria realmente de mulher? Não acreditei. Lido o volume e o retrato no jornal, balancei a cabeça: Não há ninguém com esse nome. É pilhéria. Uma garota assim fazer romance! Deve ser pseudônimo de sujeito barbado. (Duarte apud Ramos 2003: 212)

Aproveitando-se do cenário da seca que assolava o nordeste em 1915, Rachel de Queiróz escreveu um romance que ultrapassa a perspectiva de um puro regionalismo com que foi lido durante muito tempo, pois ali na narrativa também está presente um discurso de construção sobre o lugar da mulher e o papel feminino na sociedade. Embora a escritora tenha negado seu envolvimento com o movimento feminista, é possível perceber que o romance $O$ Quinze é bem marcado por estas reflexões e sua trajetória particular corroborando com a ideia de que todo texto tem a marca do sujeito que escreve. 
Cadernos de Literatura Comparada

Rachel de Queiróz e Conceição de 0 Quinze

A protagonista do romance é Conceição, uma jovem professora que transita entre o espaço do sertão e da capital espalhando pela trama da narrativa suas ideias feministas e sua incapacidade de subordinação às normas impostas tradicionalmente às mulheres. Ela é uma mulher emancipada, culta e letrada que se embebe das teorias socialistas e encontra sua liberdade e independência na educação, se constituindo como sujeito pensante por meio de suas leituras.

Chegara até a se arriscar em leituras socialistas, e justamente nessas leituras é que lhe saíam as piores das tais ideias, estranhas e absurdas à avó. Acostumada a pensar por si, a viver isolada, criara para seu uso ideias e preconceitos próprios, às vezes largos, às vezes ousados, e que pecavam principalmente pela excessiva marca de casa. (Queiróz 1937: s/p)

Assim que a mulher adentra no mundo da cultura, o magistério passa a ser considerado uma vocação feminina e por que não uma oportunidade para as solteiras, uma vez que representava uma missão sagrada de continuação da maternidade e doação incondicional ao outro, não representando assim, uma ameaça à moral e aos bons costumes. No entanto, Conceição rompe com essa ideia, pois se aproveitando da sua condição de professora, utiliza da linguagem e do discurso como prática de poder e lugar de reivindicação de direitos iguais para homens e mulheres, colocando em perigo os anseios do patriarcado como se pode perceber na seguinte passagem:

- Isso não é romance, Mãe Nácia. Você não está vendo? É um livro sério de estudo...

- De que trata? [...]

- Trata da questão feminina, da situação da mulher na sociedade, dos direitos maternais, do problema...

[...]

- Mãe Nácia, quando a gente renuncia a certas obrigações, casa, filhos, família, tem que arranjar outras coisas com que se preocupe... Senão a vida fica vazia demais... (ibidem)

Através daquelas páginas lidas com tanto afinco é que Conceição extrai ideias para seu projeto de vida e resistência aos padrões tradicionais. É verdade que nutre por seu primo Vicente um sentimento de grande estima e que em alguns momentos pensa em estar ao seu lado, mas esse desejo é interditado por várias razões que acabam adiando seu papel de mulher e esposa submissa. Talvez por não saber "amar com metade de coração" como afirma a própria Conceição, dividida entre seus desejos femininos e o engajamento de suas leituras.

Ao mesmo tempo em que pensa estar ao lado de Vicente, esse homem rude, simples, de belas feições e "busto forte", Conceição se depara com a possibilidade de um casamento frustrado, pautado na submissão da mulher ao lado de um homem adúltero. Como a mulher era subjugada pelo homem, ela lhe servia de objeto sexual e reprodutor e não podia exigir sua fidelidade dentro do matrimônio. Receosa e desiludida, Conceição se torna indiferente com Vicente, como se nota na seguinte passagem: 
Ainda sob a impressão da conversa com Chiquinha Boa a moça pensava em Vicente. E sofreu novamente o sentimento de desilusão e despeito que a magoara quando a mulher falava. "Sim, senhor! Vivia de prosear com as caboclas a até falavam muito dele com a Zefa do Zé Bernardo!" E ela, que o supunha indiferente e distante, e imaginava que, aos olhos dele, todo o resto das mulheres deste mundo se esbatia numa massa confusa e indesejada... (ibidem)

O adultério era uma prática natural e muito comum na sociedade daquela época, pois os homens poderiam gozar livremente de aventuras sexuais fora do casamento. A natureza poligâmica do macho viril não era questionada e segundo os conselhos da avó Inácia, as mulheres acabavam se acostumando a viver com esta situação. Conceição, no entanto, como mulher que se afirma como sujeito do próprio destino e que almeja a liberdade em sentido amplo, não aceita esta condição imposta à mulher como fica claro no diálogo com sua avó:

- Mas minha filha, isso acontece com todos...

[...]

- Pois eu acho uma falta de vergonha! E o Vicente, todo santinho, é pior do que os outros! A gente é morrendo e aprendendo!

Dona Inácia meteu os olhos pelo passado e recordou-se dum velho tempo em que ela vivera também aqueles rompantes e aquelas revoltas... E no fim, tudo isso é natural e de esperar, e a gente se acostuma à força...

[...]

- Minha filha, a vida é assim mesmo... Desde que o mundo é mundo... Eu até acho os homens de hoje melhores.

Conceição voltou-se rápida:

- Pois eu não! Morro e não me acostumo! É lá direto! Olhe Mãe Nácia, eu podia gostar de uma pessoa como gostasse, mas sabendo de uma história assim, não tinha santo que desse jeito! (ibidem)

Essa incapacidade de se submeter às imposições sociais leva a protagonista a renunciar à relação afetiva com Vicente, pois Conceição também começa a perceber a diferença cultural e intelectual entre ambos. Ela uma normalista, leitora de Machado de Assis, e Vicente, um vaqueiro que sabia ler apenas as notas do gado, um homem "bom de ouvir e de olhar, como uma bela paisagem", mas que não entenderia suas responsabilidades fora do lar como professora bem como sua obra social de apoio aos retirantes da seca no campo de concentração. Além do mais, esse relacionamento colocaria em ameaça a sua liberdade conquistada, pois para Vicente uma mulher não poderia sair de casa sem um "guarda de banda". E sobre estas diferenças, Conceição conclui:

[...] foi-lhe aparecendo a diferença que havia entre ambos, de gosto, de tendências, de vida. O seu pensamento, que até a pouco se dirigia ao primo como a um fim natural e feliz, esbarrou nesta encruzilhada difícil e não soube ir a diante. (ibidem) 
Cadernos de Literatura Comparada

Rachel de Queiróz e Conceição de 0 Quinze

Em alguns momentos é possível perceber a ideologia patriarcal e o desejo de Vicente de ver em Conceição uma mulher frágil, subjugada, "caída por terra" como na visão de seu sonho, sem esses atributos de independência e intelectualidade que ela possuía, pois sua visão era o perfil que se esperava de uma mulher no regime patriarcal.

Pensou em trazê-la à força, roubada, talvez, passando por cima de preconceitos e protestos, vendo-a chorar, com os grandes olhos cheios de água, os cabelos escuros rolando soltos nas costas, cobrindo-lhe a face assustada. (ibidem)

Dominar uma mulher "acostumada a pensar por si só", com ideias e conceitos "às vezes largos, às vezes ousados" como Conceição, não seria um intento tão fácil, além disso, ariscar-se e depois fracassar, colocaria em questionamento o poder fálico de sedução e conquista do masculino. Assim, Vicente toma consciência da impossibilidade de seu desejo e pouco a pouco,

[...] foi descobrindo uma Conceição desconhecida e afastada tão diferente dele próprio, que, parecia nunca coisa nenhuma os aproximara. Em vão procurou, naquela moça grave e entendida do mundo, a doce namorada que dantes pasmava com sua força, que risonhamente escutava seus galanteios [...]. (ibidem)

A problemática do corpo também está presente no texto, visto que quase não há descrições sobre o corpo físico de Conceição em sua totalidade. A imagem da protagonista está fragmentada e espalhada na narrativa de forma que se fala apenas sobre suas mãos, seus olhos, seus braços e seus cabelos sempre trançados. Pouco se sabe sobre quem é de fato Conceição por fora, essa moça "morena e esguia" que chegava à velha fazenda do Quixadá "sempre cansada, emagrecida pelos meses do professorado; e voltava mais gorda com o leite ingerido à força" (ibidem).

Aparentemente, a narrativa parece negar um corpo para Conceição, mas ele está lá, tecido às escondidas, trançado e entrelaçado no corpo do texto através de seus gestos e atitudes. Descrições fragmentadas de um corpo que revela a resistência feminina através de sua voz, suas mãos, seu olhar e seu discurso contra a dominação masculina. Ao não dar tanta visibilidade ao corpo de Conceição pode-se perceber a intenção da autora em inserir na narrativa a ideia de uma mulher pensante que se nega às amenidades do lar e às prerrogativas masculinas.

O cabelo "trançando" de Conceição evidencia a força dessa mulher que tem consciência de suas escolhas, que não se deixa assujeitar e subalternizar, pois é sua voz que a torna dona de seu corpo e seu destino. Segundo Simone de Beauvoir, "a mulher não é definida nem por seus hormônios nem por seus instintos e sim pela maneira por que reassume, através de consciências alheias, o seu corpo e sua relação com o mundo" (Beauvoir 2009: 928).

Nesse sentido, a subtração do corpo físico é compensada por descrições mais sutis que evocam a imagem de Conceição como uma mulher pensante e reflexiva, de natureza incomum, "considerada superior no meio das outras". 
A avó, que vinha de dentro, a veio encontrar ainda sentada, os olhos perdidos, o pensamento nos contos lúgubres da seca, as tranças escuras caídas ao redor do rosto pálido, as mãos no regaço do vestido branco, calada, triste, imóvel; e a velha sentou-se numa cadeira próxima, dividindo o silêncio com a neta. (Queiróz 1937: s/p)

A ausência do corpo inteiriço de Conceição parece ter a negação do desejo, burlando o papel da mulher no processo reprodutivo e reforçando a ideia de que é possível subordinar o corpo, mas não se pode deter o pensamento de uma mulher como Conceição que não se rende às regras sociais do patriarcado. Num cenário em que as mulheres assumiam o valor de uma mercadoria de troca entre as famílias abastadas, não descrever minuciosamente o corpo de Conceição na narrativa, pode ser entendido como uma forma de resistência contra o discurso patriarcal que impingiu à mulher a visão de um sujeito frágil do ponto de vista físico, intelectual e emocional por sua matriz biológica e procriadora além de um interdito sexual contra a prática do casamento patriarcal. Nesse sentido, Adriana Piscitelli também considera que "o corpo aparece, assim, como o centro de onde emana e para onde convergem a opressão sexual e a desigualdade" (Piscitelli 2004: 46).

Assim, pode-se inferir que por não estar descrito detalhadamente na narrativa, o corpo de Conceição não pode ser tocado por Vicente muito menos entregue às relações de poder mantidas pelo regime patriarcal. Se o corpo pode ser submetido ao prazer e aos desejos do homem, a fragmentação do corpo de Conceição é uma estratégia para fugir dessa dominação masculina marcando a resistência no processo de construção da subjetividade feminina.

Não há descrições sobre o corpo de Conceição no que se refere à boca, pernas, tornozelos e busto que constituem objetos de censura e obsessão erótica. Porém, a caracterização da personagem Mariinha Garcia, uma moça de "lindos olhos e uma curiosa graça no riso", por quem Vicente tem uma rápida aproximação, é pautada em descrições mais corpóreas.

[...] Vicente, que olhava o bonde e uma moça que subia, voltou-se rindo para as irmãs:

- Vejam como a Mariinha Garcia tem as pernas grossas! Lourdinha o repreendeu, também rindo:

- Você não tem vergonha! ... Deixa as pernas da moça em paz! Ele se defendeu:

- Pra que vocês andam agora com estas saias tão justas? Vão subir no bonde, mostram até a batata da perna... (Queiróz 1937: s/p)

Pelo que se pode perceber, as mulheres descritas no romance não são iguais entre si, pois o corpo de Mariinha Garcia é um "objeto" passível de ser tocado e desejado por Vicente que pode torná-lo submisso ao sistema vigente. Pode-se observar na narrativa que a moça manifesta um comportamento esperado para as mulheres de sua época, sonha em casar-se; ter uma casa e um homem digno de seu amor como se nota na seguinte passagem:

[...] a pobre Mariinha já alinhava risonhamente as primeiras peças da futura felicidade e todas as noites sonhava com uma casa muito grande e muito branca, com uns braços fortes de lutador e de apaixonado, 
Cadernos de Literatura Comparada

Rachel de Queiróz e Conceição de 0 Quinze

com um largo peito de homem onde pousaria a cabeça. (ibidem)

A fragmentação do corpo de Conceição, por sua vez, assume um jogo estratégico dentro da narrativa, pois passa a ser o centro de saberes mais apurados, de poderes mais articulados e, consequentemente, um lugar de construção de um discurso de poder e resistência feminina. As imagens fragmentadas do corpo de Conceição constituem o todo de sua personalidade, marcada pelas mãos que doam assistência aos desvalidos e que enxugam as lágrimas da avó quando se despede do sertão, pelos "olhos doloridos de tanta miséria vista" no campo de concentração bem como o olhar atento às questões femininas e à subordinação da mulher na sociedade.

Conceição representa mais que um corpo, mas uma voz dissidente que se posiciona contra a dominação masculina, demonstrando um forte engajamento político, características não-convencionais para uma mulher no início do século XX, pois não era à toa que Dona Inácia tinha o hábito de "utilizar Conceição como intérprete de língua mais expedida e bem informada" (ibidem).

Essa voz dissidente criada por Rachel de Queiróz ao dar vida a Conceição faz-nos pensar o quanto a literatura feita por mulheres reflete as angústias, os desejos e os sonhos pessoais das escritoras, uma vez que mimetizam formas de ser e de existir de sujeitos femininos que, assim como elas próprias, não se submetem ao jugo patriarcal. Para Ruth Silviano Brandão (2004) "a personagem feminina, construída e produzida no registro do masculino, não coincide com a mulher. Não é sua réplica fiel, como muitas vezes crê o leitor ingênuo. É, antes, produto de um sonho alheio" (Brandão 2004: 11). Essa representação, portanto, desconstrói o lugar da mulher e da escritora dentro na literatura canônica para muito além das possibilidades de um sujeito sem voz e sem discurso próprio.

Acostumada a pensar por si só, Conceição "torce sua natureza" rompendo com a tradição, renunciando seus desejos femininos de se casar e constituir uma família. Para resistir às pressões sociais, manter firme seus ideais de mulher revolucionária e,

para evitar o excessivo desemparo, a agente precisa criar seu ambiente, suas ideias, suas reformas, seu apostolado... Embora nunca os realize... Nem sequer os tente... Mas ao menos os projete, e mentalmente os edifique... (Queiróz 1937: s/p)

Pode-se notar, também, uma crítica velada aos padrões religiosos, pois sustentada a partir da ideologia católica, a mulher tinha seu comportamento moldado para o matrimônio, a maternidade e submissão ao marido. Unir seres tão diversos se constituía numa observância das leis divinas e da natureza, subverter essa ordem seria desobedecer a Deus. As qualidades femininas deveriam aproximar-se do modelo da virgem Maria da ideologia católica, e seus desejos voltados para a preservação da família e dos valores cristãos. No entanto, Conceição decide não se casar e não ter filhos, rompendo com o estereótipo feminino de sua época.

Indiferente à fé demonstrada pela avó por meio das súplicas e devoção aos santos, das rezas e uso do "rosário de grandes contas pretas pendurado no braço", Conceição é descrente 
quando a avó faz uma novena pedindo pela chuva e prefere ficar em casa lendo seus livros a ir à igreja, como se nota na passagem abaixo:

Maciamente, num passo resvalado de sombra, Dona Inácia entrou, de volta da igreja, com seu rosário de grandes cotas pretas pendurado no braço. Conceição só viu quando o ferrolho rangeu, abrindo:

- Já de volta, Mãe Nácia?

- E você sem largar esse livro! Até em hora de missa! A moça fechou o livro, rindo:

- Lá vem Mãe Nácia com briga! Não é domingo? Estou descansando. (ibidem)

O discurso hegemônico do patriarcalismo utilizava a religião, o casamento e a maternidade como ferramentas de controle e subordinação feminina em relação à ordem imposta pela sociedade falocêntrica o que justifica a desconfiança de Conceição nessas instituições. De acordo com Simone de Beauvoir, "o destino que a sociedade propõe tradicionalmente à mulher é o casamento. Em sua maioria, ainda hoje, as mulheres são casadas, ou foram, ou se preparam para sê-lo, ou sofrem por não o ser" (Beauvoir 1976: 165). No entanto, evidenciamos dentro do texto literário por meio do exercício da escrita de Rachel de Queiróz em, 0 Quinze, a descrença absoluta de Conceição em relação ao casamento e a escolha de não ser mãe biológica de seus próprios filhos como recusa à objetificação do corpo feminino a esses papéis socialmente constituídos.

A partir das ideias de Conceição que inclui outras perspectivas sociais, a temática da maternidade é apresentada como algo não inerente à condição feminina, devendo ser uma escolha e não uma imposição à mulher. Emancipando-se e conquistando a liberdade de decidir seu próprio destino, a mulher pode ter o controle sobre seu corpo de modo que a maternidade segundo Elisabeth Badinter,

Deixara de ser o alfa e o ômega da vida feminina. Para as mulheres abriu-se uma diversidade de modos de vida desconhecida das suas mães. Podiam dar prioridade às suas ambições pessoais, desfrutar o celibato e uma vida a dois sem filhos ou então satisfazer o desejo da maternidade, acompanhando ou não a atividade profissional. (Badinter 2010: 11)

Resistir às pressões sociais em uma sociedade onde o papel feminino ainda era fortemente marcado pelo matrimônio e a maternidade, demostra a consciência de Conceição em lutar contra a política de silenciamento e o jugo patriarcal que impunha regras ao sujeito feminino. Negociando com as estruturas de poder e com os valores do patriarcado uma vez que a literatura canônica produzida pelo gênero masculino instituiu a ideia de que as mulheres celibatárias e/ou sem filhos estariam condenadas à eterna solidão, Raquel de Queiróz traz para o texto literário por meio da personagem Conceição a perspectiva de uma maternidade social, sem reprodução, sem dominação do corpo, sem a necessidade do contato físico com o homem.

Corroborando com esse pensamento Hélène Cixous afirma que, "por um longo tempo, tem sido no corpo que as mulheres têm respondido à perseguição, à empresa familiar-conjugal de domesticação, às tentativas repetidas de castração" (Cixous 1976: s/p). Diferente das 
Cadernos de Literatura Comparada

Rachel de Queiróz e Conceição de $O$ Quinze

representações tradicionais que mostram a figura feminina por meio de descrições mais corpóreas, Conceição rompe com os parâmetros de sua época na medida em que adota atitudes diferenciadas que subvertem os modelos estereotipados produzidos pelo discurso masculino.

Se "o verdadeiro destino de toda mulher é acalentar uma criança no peito", Conceição decide criar como seu filho o afilhado Duquinha e fazer dele um "homem de bem". Nesse sentido, se não é desejável a Conceição gerar os filhos frutos do próprio ventre porque caminha na contramão das imposições sociais, é possível criar o filho de outra pessoa, doar afeto a um outro ser mesmo que não seja seu filho biológico, reinventar para além do seu corpo sua própria maternidade, pois Vicente nada mais era agora do que a imagem de um fantasma que vai sumindo num nevoeiro dourado da noite.

O fato de Rachel de Queiróz escrever e representar uma personagem feminina num território cheio de armadilhas e barreiras contra o cerceamento que impelia a atuação e produção feminina no cenário social e literário reitera a importância dos escritos de autoria feminina e a necessidade de refundar a tradição colocando as produções literárias produzidos por mulheres no cânone literário nacional.

\section{NOTAS}

* Gerusa Alves dos Santos Dias é Mestranda em estudos literários pelo Programa de Pós-Graduação em Letras-Estudos Literários (PPGL/EL), da Universidade Estadual de Montes Claros (UNIMONTES); Graduada em Letras-Espanhol pela Universidade Estadual de Montes Claros (UNIMONTES - 2004); em Letras-Português pela Universidade Metropolitana de Santos (UNIMES - 2015); em Pedagogia pela Faculdade de Filosofia, Ciências e Letras de Boa Esperança (FAFIBE - 2018); em Educação Especial pela Universidade Santa Cecília (UNISANTA - 2019); Professora Especialista em Atendimento Educacional Especializado na Rede Estadual de Ensino de Minas Gerais e experiência em Educação a Distância.

** Osmar Pereira Oliva possui graduação em Letras Português/Francês (1993), especialização (Lato Sensu) em Língua Portuguesa e Linguística (1995) e especialização (Lato Sensu) em Filosofia, pela Universidade Estadual de Montes Claros (Unimontes); mestrado em Literatura Brasileira (1999) e doutorado em Literatura Comparada (2002), ambos pela Universidade Federal de Minas Gerais (UFMG); pós-doutorado em Literatura Brasileira, pela Universidade do Estado do Rio de Janeiro (UERJ), em 2007. Atualmente, é professor na Universidade Estadual de Montes Claros. Tem experiência no ensino e na pesquisa na área de Letras, com ênfase nas Literaturas de Língua Portuguesa, atuando principalmente na investigação dos seguintes autores e temas: Eça de Queirós, Machado de Assis, Rachel de Queiroz, Clarice Lispector, Autran Dourado e Milton Hatoum, orientalismo, fantástico, corpo, gênero, literatura de Minas Gerais, literatura do século XIX. 


\section{Bibliografia}

Badinter, Elisabeth (2010), O conflito: a mulher e a mãe, Lisboa, Relógio D'Água Editores.

Beauvoir, Simone de (1967), O segundo sexo: a experiência vivida, trad. de Sérgio Milliet, São Paulo, Difusão europeia do livro.

Brandão, Ruth Silviano (2004), "A mulher escrita", in Castello Branco, Lúcia/ Brandão, Ruth Silviano (Orgs.), A mulher escrita, Rio de Janeiro, Lamparina editora, pp. 11-94.

Coelho, Nelly Novaes (1993), A literatura feminina no Brasil contemporâneo, São Paulo, Siciliano.

Cixous, Hélène (1976), "O riso da medusa", in Signs: Journal of Women in Culture and Society 1976, vol. $1, n^{0} 4$.

Duarte, Constância Lima (2003/2004), "Feminismo e literatura: discurso e história", in O Eixo e a Roda. Revista de Literatura Brasileira, v. 9/10. Belo Horizonte, pp. 195-219. Disponível em: http://www.periodicos.letras.ufmg.br/index.php/o_eixo_ea_roda/article/view/3167

Gotlib, Nádia Batella (2003), "A Literatura feita por mulheres no Brasil", in Brandão, Isabel e Muzart, Zahidé L. (Orgs.), Refazendo Nós-Ensaios sobre a Mulher e Literatura, Florianópolis, Editora Mulheres.

Muzart, Zahidé Lupinacci (1995), "A questão do cânone", in Anais do IX Encontro Nacional da ANPOLL, João Pessoa, pp. 89-99.

Piscitelli, Adriana (2004), "Reflexões em torno do gênero e feminismo", in Costa, Cláudia de Lima e Schmidt, Simone Pereira (Orgs.), Poéticas e Políticas Feministas, Florianópolis, Ed. Mulheres.

Queiróz, Rachel de (1937), O Quinze, Edição Integral.

Schmidt, Rita Terezinha (1995), "Repensando a cultura, a literatura e o espaço de autoria feminina", in Navarro, M. H. (Org.), Rompendo o silêncio: gênero e literatura na América Latina, Porto Alegre UFRGS. 